www.jmscr.igmpublication.org Impact Factor 5.244

Index Copernicus Value: 83.27

ISSN (e)-2347-176x ISSN (p) 2455-0450

crossref DOI: _https://dx.doi.org/10.18535/jmscr/v4i11.54

Journal Of Medical Science And Clinical Research

IGM Publication

An official Publication of IGM Publication

\title{
Application of Anatomical Knowledge by Final Year Dental Students of Integrated Curriculum: A Pilot Study
}

\author{
Authors \\ Htar Htar Aung ${ }^{1}$, Ankur Barua ${ }^{2}$, Anupa Sivakumar ${ }^{3}$, Khin Ma $\mathrm{Ma}^{4}$ \\ ${ }^{1}$ Department of Human Biology, School of Medicine, International Medical University Malaysia \\ Email: HtarHtarAung@imu.edu.my \\ ${ }^{2}$ Department of Community Medicine, School of Medicine, International Medical University Malaysia \\ Email: Ankur_Barua@imu.edu.my \\ ${ }^{3}$ Department of Human Biology, School of Medicine, International Medical University Malaysia \\ Email: anupa_sivakumar@imu.edu.my \\ ${ }^{4}$ Department of Human Biology, School of Medicine, International Medical University Malaysia \\ Email:mama_kihn@imu.edu.my \\ Corresponding Author \\ Htar Htar Aung \\ Department of Human Biology, School of Medicine, International, Medical University Malaysia \\ No. 126, Jalan Jalil Perkasa 19, Bukit Jalil. 57000 Kuala Lumpur, Malaysia \\ Email: HtarHtarAung@imu.edu.my, Tel: +60 327317509
}

\begin{abstract}
The integrated curriculum has been introduced in the Dental faculty of the designated institution since 2008. This study was aimed to evaluate the application of anatomical knowledge of final year undergraduate dental students of integrated curriculum, and to assess the perception of the both dental students and their lecturer on clinical application of anatomy. A cross-sectional study was conducted for 4 weeks among 40 final year undergraduate dental students and 18 lecturers. Students underwent an examination that included 6 Objective Structured Practical Examination (OSPE) and 20 One Best Answer (OBA) questions to test their application knowledge in clinical settings. A semi-structured, self-administrated questionnaire was used to identify their perceptions on the application of anatomical knowledge. The data were analysed by using SPSS 17. The Spearman's Correlation test reported a significant, strong, positive correlation between the scores of $O S P E$ and OBA. The Mann-Whitney U-test revealed statistically significant associations regarding the perception of both dental students and lecturers in terms of Problem based learning (PBL), practical sessions, Self-directed Learning (SDL), the strong surface anatomy knowledge, the usefulness of cadaver and the confidence in applying the anatomical knowledge. The present curriculum needs more interactive face to face sessions, small group discussions in practical sessions and more SDL in order to provide the strong foundations for undergraduate dental students in clinical anatomy.

Keywords: Anatomical knowledge, Application, Undergraduate, Dental student, Integrated curriculum.
\end{abstract}




\section{INTRODUCTION}

The dentistry program of a designated institution has adopted an integrated curriculum (systembased curriculum) since 2008. Students have learnt the anatomy together with the other medical sciences (physiology, pathology and etc.) in a system-based curriculum. It's a 5-years-program and there are 2 semesters in a year. Students learn the anatomy until the semester 4 (second year). The respiratory system, cardiovascular system are learnt in the semester 2 followed by the gastrointestinal system, endocrine system in semester 3 and the musculoskeletal and the nervous system in semester 4 . It also includes the problem based learning (PBL). Like no other disciplines, the learning anatomy constantly gives rise to great debates and surveys concerning what exactly should be taught and how ${ }^{[1]-[4]}$. The fact that the concrete anatomical knowledge is an integral part of dental and medical curricula which hasbeen agreed upon by the students, clinicians and anatomists. In the University of Southern California where PBL curriculum is being practiced, dental students have attained a high level of achievement in United States National Dental Boards (Part I) examinations, significantly superior to their peers working in a traditional lecture-based curriculum ${ }^{[5]}$. According to Last KS ${ }^{[6]}$, there was no difference in overall knowledge recall of second year dental students from the University of Liverpool in basic science between conventional didactic course and PBL courses. It is a frequent complaint that the knowledge of anatomy is easily forgotten. The gradual decline in anatomical knowledge is a result of reductions in time, resources and the changes in teaching methodology ${ }^{[7]}$. Thus, this study was conducted to evaluate the application of the anatomical knowledge among the final year dental students and to assess the perceptions of the students as well as the dental faculty in learning and application of anatomical knowledge.

\section{MATERIALS AND METHODS}

A cross-sectional study was conducted among 40 final year undergraduate dental students and 18 dentistry lecturers. All final year dental students and faculty members working in the dental departments of a designated institution were eligible for inclusion into this study. Individuals who were not willing to provide the informed written consent to participate in this study were excluded. Approval for the present study was obtained from the research and ethical committee of the respective institution. In order to maintain anonymity, a random code number was issued to each participant of this study while responding to the questionnaire. Informed written consent was obtained from every participant prior to the inception of the study. The study instruments were Objective Structured Practical Examination (OSPE) and One Best Answer (OBA) questions which were vetted, for standardization and difficulty level, with the help of experts in the field of anatomy and clinical dentistry. A semistructured self-administrated questionnaire including open-ended questions was used to collect the demographic information as well as to identify their perceptions on the application of anatomical knowledge. The questionnaire consisted of 17 items using a 6 point Likert scale $(0=$ strongly disagree, $1=$ disagree, $2=$ slightly disagree, $3=$ slightly agree, $4=$ agree and $5=$ strongly agree). Data were collected from dental students and their lecturers. Students underwent an examination that included 6 questions of OSPE and 20 OBA questions for an hour to test their application knowledge in clinical settings. The students were encouraged to complete the test on voluntary basis during sessions organized for this specific purpose. The data collected also included the questionnaires to identify their perceptions. For clinical lecturers, the open-ended questionnaires were distributed to identify their perceptions on the anatomical knowledge of the students. The data collected were tabulated and analysed by using the Statistical Package for Social Sciences (SPSS) version 17.0. The results 
were expressed in terms of proportion, median and interquartile Range (IQR). Mann-Whitney U-test and Spearman's Correlation Coefficient were applied for comparison purposes. In this study, a $p$-value $<0.05$ was considered as statistically significant.

\section{RESULTS}

All students were Chinese and Malaysians. Among them, 17 students (42.5\%) were male and 23 students $(57.5 \%)$ were female. Most of the lecturers $(78 \%)$ were Indian nationality and male $(83 \%)$ were more common than female $(17 \%)$. In terms of the students' application of knowledge, the median scores of the students for OBA and OSPE were 14 (IQR 13-15) and 22 (IQR 18-26) respectively (table 1). The students answered 20 OBAs. They chose the one best answer from the five options for each OBA. The time allowed for OBAs was 30 minutes and the total marks were 20. OSPE questions were the picture-based questions. The total marks for 6 OSPE were 60 and the time allowed was 30 minutes. Both OBA and OSPE questions were designated to apply their anatomical knowledge. Thirty-six students (90\%) passed in OBA and the only one student (4\%) passed in OSPE of an hour exam testing their application knowledge in clinical settings. The Spearman's Correlation test reported a significant, strong, positive correlation between the scores of OSPE and OBA.

Table 2 summarized the perceptions of the students and the faculty in learning and application of the anatomical knowledge. The Mann-Whitney U-test revealed a statistically significant association regarding the perception of both dental students and lecturers in terms of the strong surface anatomy knowledge and the confidence in application of anatomical knowledge. In terms of the strong knowledge for clinical application in gross anatomy and radiological anatomy, both the students and the lecturers chose the score 3 (slightly agree) while for the neuroanatomy, microscopic anatomy and developmental anatomy, they rated the score 2 (slightly disagree). Regarding the perception in the adequacy of the level of knowledge on clinically relevant anatomy, the median scores of both the students and the lecturers were the same (slightly agree). The Mann-Whitney U-test also revealed a statistically significant association regarding the perception of the students and the faculty on the usefulness of cadaver in learning anatomy. In terms of perception of usefulness of plastic models, the median score of the students was higher than that of the lecturers. This difference of opinions was not found to be statistically significant. Similarly, there wasno statistically significance association in the perception of the plastinated specimens as a learning resource in studying clinical anatomy. Though the students perceived that plastic models were more useful in learning clinical anatomy, the lecturers perceived that cadavers were the best and followed by the plastinated specimens and plastic models. In terms of PBL, practical sessions and SDL, the Mann-Whitney U-test also revealed a statistically significant association regarding the perceptions of the students and the lecturers. The learning anatomy in the integrated curriculum has had a positive impact on the students' application of knowledge in the clinical practice. Furthermore, the lecturers suggested that the improvement of the students' anatomical knowledge needs more practical sessions, 3D models and clinical scenarios in areas where the student performance is weak.

. Table. 1Scores of the students' application of anatomical knowledge

$\begin{array}{lll}\text { Assessment } & \text { Median } & \text { IQR } \\ \text { OBA } & 14 & 13-15 \\ \text { OSPE } & 22 & 18-26\end{array}$


Table.2 Perceptions of the Students and Faculty in Learning and Application of Anatomical Knowledge

\begin{tabular}{|c|c|c|c|c|c|c|}
\hline & \multicolumn{2}{|c|}{ Student's score } & \multicolumn{2}{|c|}{ Lecturer's score } & \multirow{2}{*}{$\begin{array}{l}\text { Mann- } \\
\text { Whitney } \\
\text { U-test }\end{array}$} & \multirow[t]{2}{*}{$\mathrm{P}$ value } \\
\hline & Median & IQR & Median & IQR & & \\
\hline $\begin{array}{l}\text { 1. I believe that my surface anatomy knowledge is } \\
\text { strong for clinical application. }\end{array}$ & 3 & $2-3$ & 3 & $3-4$ & 220 & $0.011 *$ \\
\hline $\begin{array}{l}\text { 2. I feel that my gross anatomy knowledge is strong for } \\
\text { clinical application. }\end{array}$ & 3 & $\begin{array}{l}2.25- \\
3\end{array}$ & 3 & $3-4$ & 276 & 0.111 \\
\hline $\begin{array}{l}\text { 3. I feel my radiological anatomy knowledge is strong } \\
\text { for clinical application. }\end{array}$ & 3 & $2-3$ & 3 & $2-3$ & 337 & 0.679 \\
\hline $\begin{array}{l}\text { 4. I feel my neuroanatomy knowledge is strong for } \\
\text { clinical application. }\end{array}$ & 2 & $2-3$ & 2 & $2-3$ & 332.5 & 0.595 \\
\hline $\begin{array}{l}\text { 5. I feel my microscopic anatomy knowledge is strong } \\
\text { for clinical application. }\end{array}$ & 2 & $2-3$ & 2.5 & $2-3$ & 283 & 0.160 \\
\hline $\begin{array}{l}\text { 6. I feel my developmental anatomy knowledge is strong } \\
\text { for clinical application. }\end{array}$ & 2 & $2-3$ & 2 & $2-3$ & 277 & 0.136 \\
\hline $\begin{array}{l}\text { 7. I have confidence in applying anatomical knowledge } \\
\text { during my clinical practice. }\end{array}$ & 3 & $2-3$ & 3 & $3-4$ & 217 & $0.009 *$ \\
\hline $\begin{array}{l}\text { 8. I believe that the level of knowledge on clinically } \\
\text { relevant anatomy is adequate to make me safe dental } \\
\text { practitioner. }\end{array}$ & 3 & $3-4$ & 3 & $3-4$ & 299.5 & 0.274 \\
\hline $\begin{array}{l}\text { 9. I regularly review my anatomy notes during my } \\
\text { dental practice. }\end{array}$ & 2 & $\begin{array}{l}1.25- \\
3\end{array}$ & 2.5 & $2-3$ & 312 & 0.398 \\
\hline $\begin{array}{l}\text { 10. I feel that cadavers are useful in learning clinical } \\
\text { anatomy. }\end{array}$ & 3 & $2-4$ & 4 & $3-4.25$ & 233 & $0.026^{*}$ \\
\hline $\begin{array}{l}\text { 11. I feel that plastic models are useful in learning } \\
\text { clinical anatomy. }\end{array}$ & 4 & $3-4$ & 3 & $2-4$ & 310 & 0.365 \\
\hline $\begin{array}{l}\text { 12. I feel that plastinated specimens are useful in } \\
\text { learning clinical anatomy. }\end{array}$ & 3 & $3-4$ & 3.5 & $2.75-4$ & 336.5 & 0.674 \\
\hline $\begin{array}{l}\text { 13. I feel that lectures are useful in learning clinical } \\
\text { anatomy. }\end{array}$ & 3.5 & $3-4$ & 3 & $2-4$ & 316 & 0.434 \\
\hline $\begin{array}{l}\text { 14. I feel that problem based learnings (PBLs) are useful } \\
\text { in learning clinical anatomy. }\end{array}$ & 3 & $2-3$ & 3 & $3-5$ & 208 & $0.007^{*}$ \\
\hline $\begin{array}{l}\text { 15. I feel that practical sessions are useful in learning } \\
\text { clinical anatomy. }\end{array}$ & 3 & $3-4$ & 5 & $4-5$ & 114.5 & $\begin{array}{l}0.0001 \\
*\end{array}$ \\
\hline $\begin{array}{l}\text { 16. I feel self-directed learning (SDL) sessions are } \\
\text { useful in learning clinical anatomy. }\end{array}$ & 2 & $2-3$ & 3.5 & $3-4$ & 184 & $0.002 *$ \\
\hline $\begin{array}{l}\text { 17. I feel that present curriculum is effective for me to } \\
\text { gain enough anatomical knowledge. }\end{array}$ & 3 & $\begin{array}{l}2- \\
3.75\end{array}$ & 3.5 & $2.75-4$ & 248 & 0.050 \\
\hline
\end{tabular}

[*Here, $p$-value $\leq 0.05$ was considered as statistically significant.]

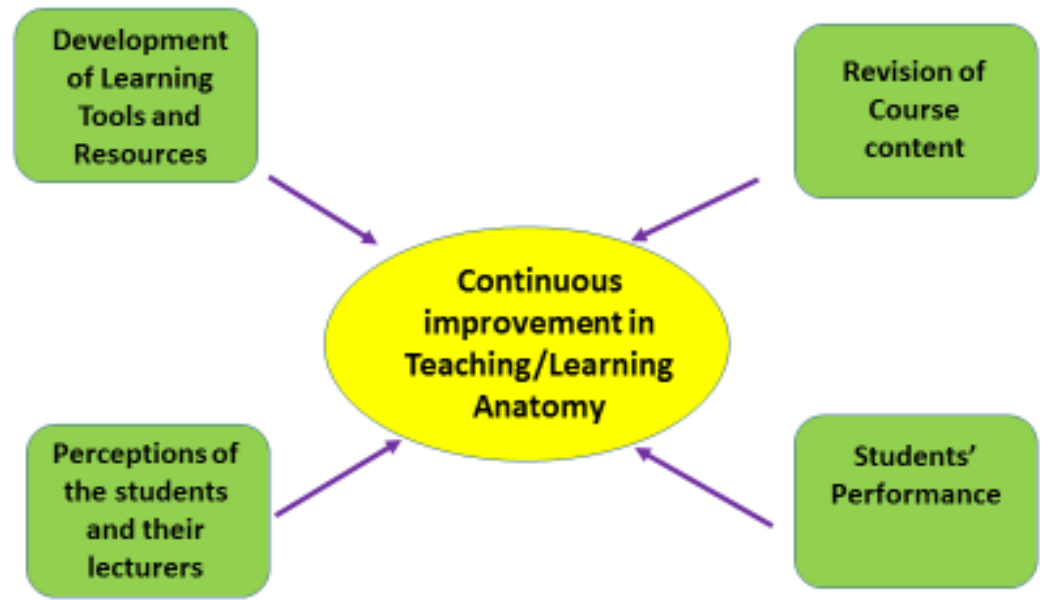

Fig. 1 Approaches for the continuous improvement in Teaching/Learning Anatomy 


\section{DISCUSSIONS}

The test for recall of factual knowledge in anatomy, biochemistry, physiology and oral biology was conducted among $2^{\text {nd }}, 3^{\text {rd }}$, and $4^{\text {th }}$ year undergraduate dental students in University of Liverpool. The performance of $4^{\text {th }}$ year dental students on the knowledge questionnaire in basic science decreased compare to $2^{\text {nd }}$ year dental students in biochemistry and to a lesser extent in anatomy ${ }^{[8]}$. In our study, OBA and OSPE were conducted among the final year dental students to test their application of anatomical knowledge that had been learnt in the second year. The scores of the test in the present study supported the previous studies on the knowledge loss of the students in basic sciences ${ }^{[8]-[11]}$. The performance of our students was weak in OSPE and the psychomotor skills of the students weren't strong enough to apply the anatomical knowledge in the clinical practice.

The previous research had shown that the score on the surface anatomy of the students who were exposed to the old curriculum was higher than those who undertook the system based curriculum at Queen's University of Belfast, UK ${ }^{[12]}$. In our study, the students who have been exposed to the system based curriculum also slightly agreed that their knowledge on the surface anatomy, gross anatomy and the radiological anatomy were strong for clinical application. In terms of the neuroanatomy knowledge, the present study agreed with the findings of Mateen FJ ${ }^{[11]}$ who revealed that the most of graduating medical students couldn't pass the multiple choice questions of a first year exam in the basic neurosciences. Our students also slightly disagreed that their knowledge on the neuroanatomy, microscopic anatomy and the developmental anatomy were strong for clinical application.

In terms of usefulness of cadaver in learning clinical anatomy, the perception of the lecturers supported the previous studies which revealed that the cadaver dissection is the most powerful teaching aid and also useful for research in clinical anatomy. It also improves the communication and teamwork skills of the students and deepens the understanding of human anatomy by providing a three-dimensional structure ${ }^{[13]-[15]}$. The perceptions of the lecturers from the present study agreed with the above studies by rating the higher scores to the usefulness of the cadaver than the plastic models and plastinated specimens. On the other hand, Azer SA ${ }^{[16]}$ revealed that the handling of cadavers has a risk of infection hazards. It was strengthened by the perception of our students who scored the usefulness of plastic model higher than the cadaver and the plastinated specimens.

At University of Southern California, School of Dentistry, in a pre-clinical and clinical program, four-year measurement of mock patient examinations and follow-up clinic patient examinations using a PBL methodology, student performance of nonsurgical periodontics skills was at an equal level to or greater than that of a conventional approach ${ }^{[17]}$. In our study, the perception of the students and lecturers were positive on the usefulness of PBL in learning anatomy although there was a statistically significant association between the perceptions of the students and the lecturers. The lecturers need to make every group members participate in the discussion to encourage the decision making and critical thinking skills. In terms of SDL, our students slightly disagreed with its usefulness in learning clinical anatomy. It was supported by the baseline SDL behaviour of the medical students at University of Uyo which were low to moderate based on the perceptions of faculty leadership and the Self-rating scale for SDL ${ }^{[18]}$. The faculty needs to standardise SDL curricula and to determine the effectiveness of the components on the educational outcomes.

In terms of the effectiveness of the present curriculum, the perceptions of both the students and the lecturers were positive in our study. The provision of the content that is relevant and appropriate to the needs of the students, the adequacy of the learning resources, and the improvement in methods of teaching are very important to enhance the students' learning. The 
evaluation of the students' performance and assessing the perceptions of both students and the faculty are necessary in order to take the remedial measures (e.g., the revision of the course content, development of the teaching/learning tools and the resources) for the continuous improvement in learning anatomy (Fig 1).

\section{CONCLUSION}

The learning anatomy in the integrated curriculum needs more interactive face to face sessions, small group discussions in practical sessions and more SDL with the plastic models to provide the strong foundations for undergraduate dental students in clinical anatomy. The structured approach to teaching psychomotor skills is required to enhance the learner performance.

\section{ACKNOWLEDGEMENT}

We are very grateful to all the final year dental students and the lecturers who participated in the study

\section{REFERENCES}

1. Cahill DR, Leonard RJ. Missteps and masquerade in American medical academe: Clinical anatomists call for action. Clinical Anatomy. 1999; 12, pp.220-222.

2. Cahill DR, Leonard RJ, Marks SC Jr. A comment on recent teaching of human anatomy in the United States. Surgical Radiological Anatomy. 2000;22, pp.69-71.

3. Heylings DJ. The curriculum, who teaches it and how? Med Edu. 2002; 36, pp.702710.

4. Miller SA, Perrotti W, Silverthorn DU, Dalley AF, Rarey KE. From college to clinic: reasoning overmemorization is key for understanding anatomy. Anat Rec. 2002; 269, pp.69-80.

5. AG Fincham and CF Shuler. The changing face of dental education: the impact of PBL. Journal of Dental Education. 2001; 65(5), pp.406-421.
6. Last K. S., Appleton J. and Stevenson, H. Basic science knowledge of dental students on conventional and problembased learning (PBL) courses at Liverpool. European Journal of Dental Education. 2001; 5, pp.148-154.

7. BW Turney. Anatomy in modern curriculum. Ann R Coll Surg Engl. 2007; 89, pp.104-107.

8. Last K. S., Appleton J., Ferguson D. B. and Stevenson, $H$. The value of questionnaire in assessing the acquisition and retention of basic science knowledge by dental students. European Journal of Dental Education. 2000;4, pp.3-9.

9. Marcel FD. Knowledge loss of medical students on first year basic science courses at the University of Saskatchewan. BMC Medical Education. 2006; 6, pp.5.

10. Harrisons A. Using knowledge decrement to compare medical student's long term retention of self-study and lecture materials. Assess and Eval in Higher Educ. 1995; 20, pp.149-159.

11. Mateen FJ, D'Eon MF. Neuroanatomy: a single institution study of knowledge loss. Med Teach.2008; 30(5), pp.537-539.

12. McKeow PP, Heylings DJA, Stevenson M, McKelvey KJ, Nixon JR, McCluskey DR. The impact of curricular change on medical student's knowledge of anatomy. MedEduc. 2003;37(11), pp.954-961.

13. Othman Mansor. Use of Plastinated specimen in a medical school with a fully integrated curriculum. JISP 1996; 11(1), pp.16-17.

14. Drake RL. A unique, innovative, and clinically oriented approach to anatomy education. AcadMed 2007; 82(5), pp.475478.

15. Nnodim JO, Ohanaka EC, Osuji CU. A follow-up comparative study of two modesof learning anatomy: by dissection and from prosections. Clinical Anatomy. 1996; 9(4), pp.258-262. 
16. Azer SA, Eizenberg N. Do we need dissection in an intergrated problembasedlearning medicalcourse? Perceptions of first - and second-year students. Sur Radiol Anat.course? Perceptions of first and second-year students. Sur Radiol Anat.2007; 29(2),pp.173-180.

17. Rich SK, Keim RG, Shuler CF. Problem Based Learning Versus a Traditional Education Methodology: A Comparison of Preclinical and clinical Periodontics Performance. Journal of Dental Educ Assoc. 2005; 69(6), pp.649-662.

18. Timothy Eyo Nottidge. Self-directed learning: Status of final year students and perceptions of faculty leadership in a Nigerian medical school - a mixed analysis study. 2014. 